\title{
Effect of Rating Modification on a Fuzzy-Based Modular Architecture for Medical Device Design and Development
}

\author{
Celestine C. Aguwa, ${ }^{1}$ Leslie Monplaisir, ${ }^{1}$ and Prasanth A. Sylajakumari² \\ ${ }^{1}$ Industrial and Systems Engineering, Wayne State University, 4851 Fourth Street, Detroit, MI 48201, USA \\ ${ }^{2}$ Mechanical Engineering Department, PSG College of Technology, Coimbatore, India
}

Correspondence should be addressed to Celestine C. Aguwa, celestine.aguwa@wayne.edu

Received 28 March 2012; Revised 31 July 2012; Accepted 31 August 2012

Academic Editor: Ajith Abraham

Copyright (C) 2012 Celestine C. Aguwa et al. This is an open access article distributed under the Creative Commons Attribution License, which permits unrestricted use, distribution, and reproduction in any medium, provided the original work is properly cited.

\begin{abstract}
The goal of this research is to determine the effect of customer ratings on the optimal number of modules for medical device design. Medical devices have a $90 \%$ failure rate in their first prototype tests according to the international testing body, Intertek. To address this key issue of quality, we present an integrated, collaborative, modular architecture method for medical device design and development. A typical glucometer is used as proof of concept to demonstrate the methodology and analyze the impact of changing the customer ratings on the optimal number of modules and minimum deviation. The implication of this research is to generate scholarly work and to reduce the number of potential failure points in medical devices by determining the optimal number of modules.
\end{abstract}

\section{Introduction}

This paper focuses on developing more synergy between key engineering concepts and the medical profession. The overall objective is to improve patients' quality of medical treatment and safety. In our earlier research, we presented a procedure for the determination of optimal modules for a medical device [1]. Subsequently, we determined that rule changes affect the final outcome [2]. Herein, we present our confirmation of the effect of ratings change from the stakeholders on the final optimized number of modules. The implication of these investigations is that good analysis of data input enables better quality of patient care.

For example, in diabetes care, it is important that correct blood glucose readings are recorded. To do this requires reliable and accurate equipment consisting of both the meter reader and the strips. For the meter reading to be accurate, the data input from the subject is very important. In an earlier paper $[1,2]$, several measurements were collected to measure the impact of meter data input to evaluate the accuracy and reliability of the glucometer. The importance of proper care for diabetes and its impact on the healthcare industry is fully stated in that paper. These were addressed through the architecture modeling of the components as explained in the following paragraph.

Architectural selections made during the early stages of development are key decisions, as they have profound impact on the product costs, quality, and manufacturability [3]. Poor architecture increases costs by forcing companies to pay for launch difficulties, late engineering modifications, difficult part fabrication, inefficient assembly, and excessive part proliferation $[3,4]$. This can be overcome by a modular design strategy. This strategy decomposes complex products and systems into simpler subsystems, thereby allowing us to efficiently manage and develop complex products and systems $[5,6]$. A modular design strategy is also considered to be an enabling technology for developing a large variety of products with reliability and maintainability at reduced costs and development time [7, 8]. Sony [9] and Volkswagen [5] have shown clear benefits from adopting a modular product strategy. A number of analytical models for product family design have been successfully developed and tested $[10,11]$. However, unlike product family design, limited attempts have been made in developing such approaches for module identifications. 


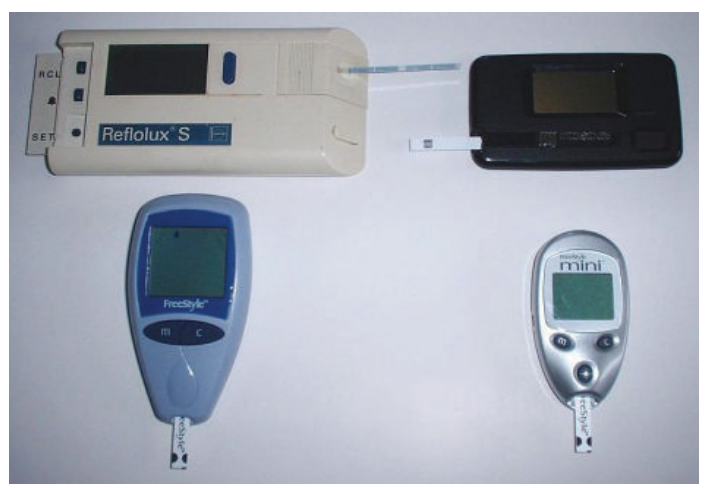

FIGURE 1: Four generations of blood glucose meter, c. 1993-2005.

\section{Problem Statement and Motivation}

As earlier stated, the core problem addressed in this paper is to investigate the effects of ratings on the outcome. We believe that this is paramount to the reliability of the product by assigning the correct components to the right module. Intertek [12], a worldwide independent testing, inspection, and certification company, tests thousands of medical devices each year to determine their conformity to appropriate standards and regulations. They report that almost all medical devices (90\%) fail to conform to specifications during their first tests. This level of failure should be unacceptable to any medical device manufacturing firm, since it directly impacts product quality, reliability, and ultimately customer satisfaction. Quality and reliability issues need to be considered earlier in the product development stage to reduce failure rates.

In this paper, we attempt to improve on the conformance of medical devices and achieve an overall improvement in medical devices by finding the optimal number of modules to implement a modular design strategy. This research is focused on the study of the impact of stakeholder ratings on the optimal number of modules. In Section 3, we present a literature review followed by our proposed methodology in Section 4. Section 5 contains the proof of concept using a typical glucometer, which has an acceptable reading error range of $\pm 20 \%$ at glucose concentrations of $4.20 \mathrm{mmol} / \mathrm{L}$ or above [13]. Finally, we present the evaluation and conclusion in Sections 6 and 7, respectively. See Figures 1 and 2 for samples of the glucometer and test strip process, respectively, for our case study.

\section{Literature Review}

In this section, we present modular design strategy research done with varying degrees of success by other scientists. The majority of the reviewed research applied these methods to the automotive sector. In this paper, we apply these methods to the medical devices area.

3.1. Healthcare Devices-Medical Devices. Medical device development has been addressed by several authors with encouraging success. An attribute-driven concurrent engineering (ADCE) process for the development of medical

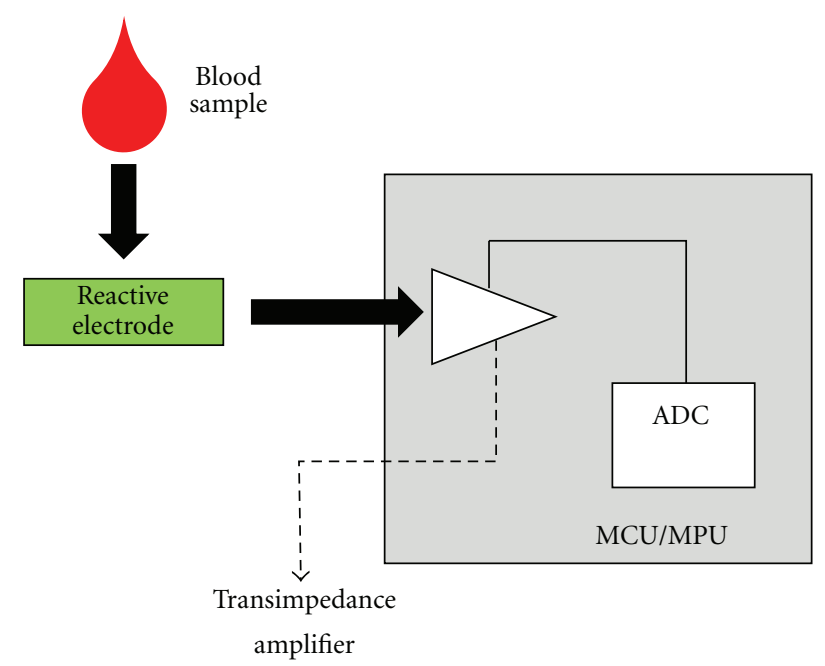

Figure 2: Test strip basic block diagram (http://www.eetimes .com/design/test-and-measurement/4204495/Blood-Glucose-Meter-Design).

devices has been proposed [14]. This involves the formulation of attribute-driven specifications (ADS) and an attribute-driven design control. In a collaborative approach, data management is essential [15]. Data communication among stakeholders enables the project's successful execution due to the stringent requirements and regulations imposed on the manufacturers [16]. Quality is a key issue in medical device design and manufacturing. Therefore, these regulations require that submissions to medical device regulatory bodies for approval must include any biological evaluation results [14].

3.2. Product Modularization. Product modularization has gained interest in both academia and industry. Modularization geared towards product families has been successfully implemented on a engineered-to-order product, for example, an industrial steam turbine. This indicates that modularization techniques work in applications involving mass customization. Mass customization effectively shortens lead-time and noticeably reduces production costs of the steam turbine [17]. Determining the product architecture is one of the key activities of any industrial product development. System architecting involves clustering various components within a product so that the resulting modules are effective for the company. An ideal architecture is one that partitions the product into practical and useful modules. Quality issues can be better addressed at the early stages of product design by integrating quality with modular design concepts [18].

\subsection{Application of Fuzzy Logic in Product Development.} Fuzzy systems have been applied in several fields where qualitative data is an issue [19-24]. Estimating a product's manufacturing cost is a key component of the concept development stage. Traditional parametric and generativebased models cannot adopt a fuzzy logic-based methodology for estimating a product's manufacturing cost because of the generally unclear and subjective nature of the data [25-27]. 


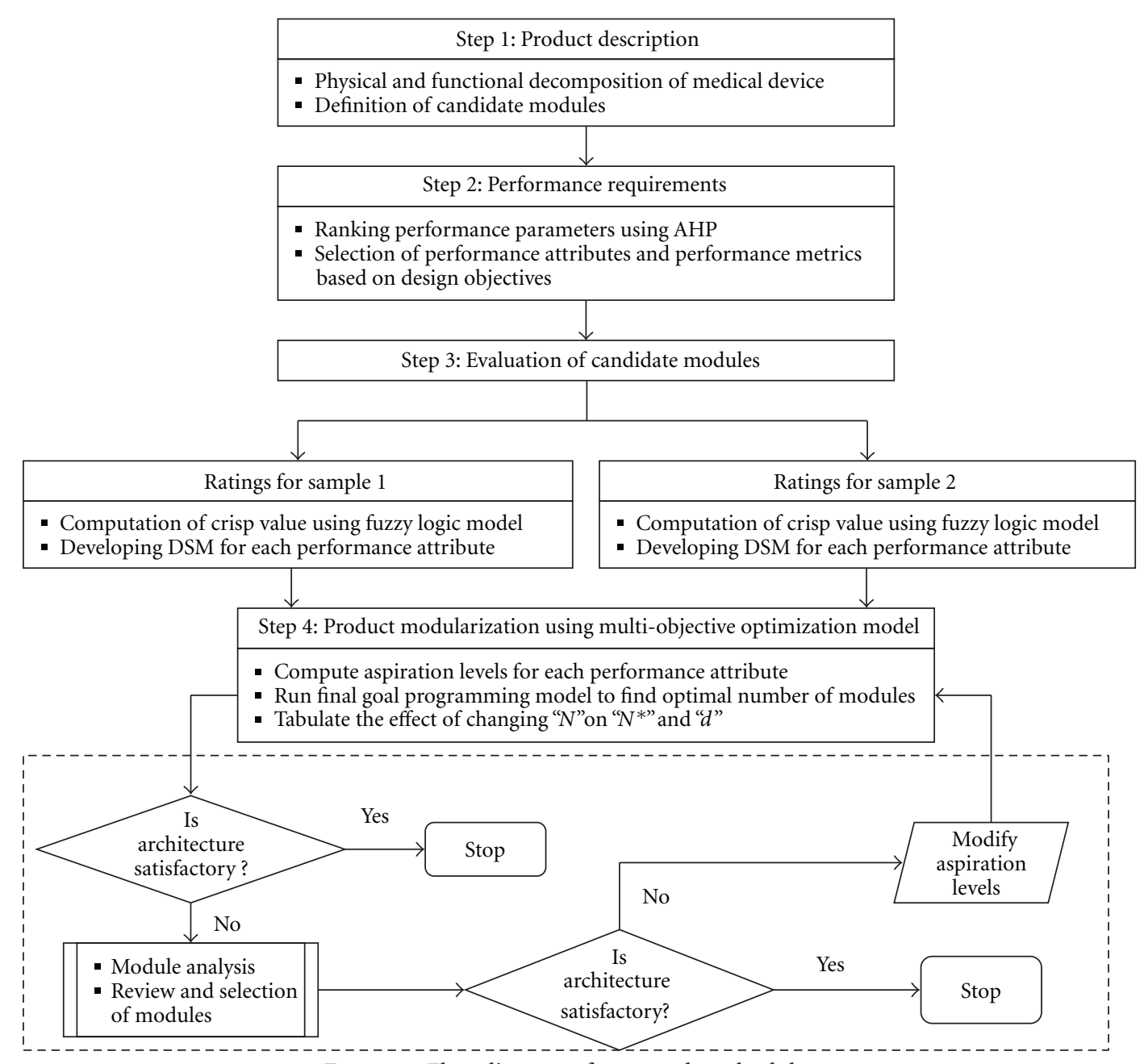

FIgURE 3: Flow diagram of proposed methodology.

We present here a fuzzy-based theory and methodology that represents imprecise and conflicting customer requirements, yet facilitates the communication between multidisciplinary team members while implementing a quality function deployment (QFD) process for product development projects [28]. Reliability analysis and monitoring product reliability improvement at different stages of the product development process are the other significant contributions of fuzzy logic-based studies in the product development area.

The fuzzy methodology applied in this work is the Takagi and Sugeno [19] method of fuzzy inference. Introduced in 1985, it is similar to the Mamdani [19] method in many respects. The first two parts of the fuzzy inference process, fuzzifying the inputs and applying the fuzzy operator, are exactly the same. The main difference between Mamdani and Sugeno is that the Sugeno output membership functions are either linear or constant, and the defuzzification part is not required.

\section{Methodology}

In this section, we discuss the steps involved in medical device product development and determining the optimal number of modules using goal programming [1].
4.1. Proposed Methodology. The specific goals of this research are to determine design criteria by collaborating with users and manufacturers of medical equipment; translate those stakeholder inputs into specific design targets; develop a preliminary modular design framework using multicriteria optimization methods; test the preliminary modular architecture using a simple medical device and, eventually, study the impact of stakeholder ratings on the optimal number of modules and minimum deviation $d$. Our goal with this research is to ultimately lead to improved device quality, reliability, and therefore patient safety. Our proposed methodology for product modularization during the conceptual stage follows a systems engineering approach that consists of four steps as shown in Figure 3.

4.2. Medical Device Product Development. The following sections describe each step of the proposed methodology in detail as shown in Figure 3. The first step in the methodology is the functional and physical decomposition analyses of a medical device or system. A list of basic components is identified from which a number of candidate modules are constituted in pairs. Thus, the performance evaluation will be centered on pair-wise interaction between components. 
In step 2, a preliminary assessment is completed using the Analytical Hierarchical Process (AHP) [29] method to identify and rank the parameters or attributes: quality, reliability, cost, and ease of development (EOD). Performance metrics for each of these attributes are also identified.

Step 3 consists of two tasks. The first task develops a formal, structured process for engineering judgment of candidate modules with respect to the selected design objective metrics. The second task develops a fuzzy logic model for transforming these subjective judgments into a set of crisp performance indices. Individual crisp values are then entered in a matrix form to generate one of the index matrices: Quality and Robustness Index (QRI), Reliability and Maintainability Index (RMI), Ease of Development Index (EODI), and Cost Performance Index (CPI). These decision structure matrices (DSM) [30] help factor in the crisp fuzzy output values of the qualitative stakeholder data into the optimization model. Step 3 is applied to data from two different stakeholders-stakeholder rating 1 and stakeholder rating 2 .

In step 4, four individual optimization models are run for each of the parameters: quality, Reliability, EOD, and Cost. The objective function value $\left(Z_{q}, Z_{r}, Z_{e}, Z_{c}\right)$ of each model determines the aspiration levels $\left(A_{q}, A_{r}, A_{e}, A_{c}\right)$ for the Goal program to be run. We use the Goal Programming (GP) model for optimizing contrasting objectives-namely, maximization of quality, reliability, ease of development (EOD), and minimization of cost. The number of median components are used as decision variables to determine the optimal number of modules, $N^{*}$ [31]. The details of the mathematical model are as follows.

Decision Variables and Parameters for

Individual Optimizations

$$
X_{i j}= \begin{cases}1, & \text { if component } i \text { belongs to component } \\ & \text { family/module } j \\ 0, & \text { otherwise }\end{cases}
$$

$N$ = predefined number of modules for a product

(number of median components - a subjective decision of OEM),

$Q_{i j}=\mathrm{QRI}$ with respect to components $i$ and $j$ when both of them are in the same module,

$R_{i j}=$ RMI with respect to components $i$ and $j$ when both of them are in the same module,

$E_{i j}=$ EODI with respect to components $i$ and $j$ when both of them are in the same module,

$C_{i j}=$ CPI with respect to components $i$ and $j$ when both of them are in the same module,

$Z_{q}, Z_{r}, Z_{e}, Z_{c}=$ goal functions for quality, reliability, ease of development, and cost, respectively.

\section{Objective Function}

$$
\begin{aligned}
& \text { Maximize } Z_{q}=\sum_{i} \sum_{j} Q_{i j} * X_{i j} . \\
& \text { Maximize } Z_{r}=\sum_{i} \sum_{j} R_{i j} * X_{i j} . \\
& \text { Maximize } Z_{e}=\sum_{i} \sum_{j} E_{i j} * X_{i j} . \\
& \text { Minimize } Z_{c}=\sum_{i} \sum_{j} C_{i j} * X_{i j} .
\end{aligned}
$$

Subject to:

$\sum_{j=1}^{n} X_{i j}=1 \quad \forall i$ (one component-one module constraint)

$X_{i j} \leq X_{j j} \quad \forall i, \forall j$ (median component constraint),

$\sum_{j=1}^{n} X_{j j}=N \quad$ (all components assigned to predefined

number of modules),

$X_{j j}=0 / 1 \quad \forall i, \forall j$ (binary constraints).

Decision Variables and Parameters for the Goal Programming Model

$X_{i j}= \begin{cases}1, & \text { if component } i \text { belongs to component } \\ \text { family/module } j & \\ 0, & \text { otherwise }\end{cases}$

$d=$ worst unwanted deviation from design goals,

$Q_{i j}=$ QRI with respect to components $i$ and $j$ when both of them are in the same module,

$R_{i j}=$ RMI with respect to components $i$ and $j$ when both of them are in the same module,

$E_{i j}=$ EoDI with respect to components $i$ and $j$ when both of them are in the same module,

$C_{i j}=$ CPI index with respect to components $i$ and $j$ when both of them are in the same module,

$A_{q}, A_{r}, A_{e}, A_{c}=$ aspiration levels for quality, reliability, EoD, and cost, respectively. 
Objective Function: Minimized. Subject to:

$$
\begin{aligned}
& \sum_{j=1}^{n} X_{i j}=1 \quad \forall i \\
& \sum_{j=1}^{n} \sum_{i=1}^{n} Q_{i j} * X_{i j}+d \geq A_{q} \quad \text { (quality goal constraint), } \\
& \sum_{j=1}^{n} \sum_{i=1}^{n} R_{i j} * X_{i j}+d \geq A_{r} \quad \text { (reliability goal constraint), } \\
& \sum_{j=1}^{n} \sum_{i=1}^{n} E_{i j} * X_{i j}+d \geq A_{e} \quad \text { (EoD goal constraint), } \\
& \sum_{j=1}^{n} \sum_{i=1}^{n} C_{i j} * X_{i j}-d \leq A_{c} \quad \text { (cost goal constraint), } \\
& X_{i j}=0 / 1 \quad \forall i, \forall j \text { (binary constraints). }
\end{aligned}
$$

\section{Glucometer Case Study}

The following sections describe each step of the proposed methodology as shown in Figure 3, applied to a standard glucometer shown in Figure 1 in detail.

5.1. Step 1: Product Description. The basic components of a glucometer were identified from the patent of a wearable glucometer [32] as proof of concept. In discussions with OEMs, the typical parameters for a glucometer are selected (quality, reliability, ease of development (EOD), and cost) as performance attributes of interest or design objectives of modularization.

\subsection{Step 2: Performance Requirements}

5.2.1. AHP to Decide Parameter Selection. The AHP output of the priorities from Expert Choice is shown in Figure 4. The overall inconsistency is 0.07 which is well below the accepted level of 0.10 . Therefore the initial optimization problem should be solved in the following order: quality, reliability, ease of development, and cost.

5.2.2. Quality Metrics. In step 2, the most critical task is to identify an appropriate set of metrics to measure the earlier-defined product design or performance attributes. As a working definition, a performance attribute metric is defined as the factor that significantly influences it. Quality can be built into the product at the design phase by axiomatic design [33]. According to Deming, the customer's definition of quality is the only one that matters. The three objectives of product design for quality are as follows: meet customer expectations, be robust, and be reliable [34]. Based on these objectives, we selected the customer perceived quality (CPQ), robustness, and axiomatic compliance metrics as metrics for quality. The ten-point scale goes from a high rating of 10 (very high), where the module significantly complies with industry standards and requirements, to a rating of 1 (very low), where the module does not meet requirements [1]. Tables 1 and 2 show the quality metrics along with two different stakeholder ratings.

5.2.3. Reliability Metrics. Reliability allocation allocates the entire target reliability of a product into its subsystem and again, allocates the subtarget reliability of each subsystem to the parts level [1]. The metrics for reliability are critical failure, maintainability, and serviceability. Tables 1 and 2 show the reliability metrics along with two different stakeholder ratings.

5.2.4. Ease of Development (EOD) Metrics. EOD is defined as the ease with which modules can be designed and assembled; a metric that is required for tracking changes and to prevent any assembly complications [1]. EOD metrics are manufacturability of the module and functional interaction between the components. Tables 1 and 2 show the EOD metrics along with two different stakeholder ratings.

5.2.5. Cost Metrics. Cost is a critical parameter [1]. Various metrics are associated with product development. For this study, however, we limited the scope to only fixed costs, cost of interfacing, and cost of reusability. Tables 1 and 2 show the cost metrics along with two different stakeholder ratings.

5.3. Step 3: Evaluation of Candidate Modules. Each of these stakeholder ratings are entered into the Sugeno fuzzy model. Based on the rules defined in the Sugeno engine, a crisp output value is calculated for each row of pair-wise interaction stakeholder rating. Table 3 shows the inputs and outputs to the fuzzy model.

In Figure 5, quality metrics ratings for a candidate module with two components for Stakeholder 1 rating are evaluated with respect to $\mathrm{CPQ}$, robustness, and compliance to axiomatic design, respectively. We consider a candidate module, comprising of acoustic transducer and light provider, in order to discuss how the fuzzy logic model is used to compute the QRI. During the aggregation of the output for QRI, 25 rules are defined for the candidate module defined above. For example; rule \#17: if (CPQ is high) and (robustness is high) and (axiomatic compliance is very low), then ( $Q R I$ is moderate). Once the three input variable values (9 (CPQ), 8 (robustness), 9 (axiomatic compliance)) are entered into the rule viewer of the Sugeno model, it computes the crisp QRI value for stakeholder 1 rating as 8.61 as shown in Figure 5(a). The corresponding QRI value for stakeholder 2 rating is shown in Figure 5(b). The QRI index for the remaining prospective candidate modules are determined and presented in a QRI matrix format for stakeholder 1 rating as shown in Figure 6, and for stakeholder 2 rating as shown in Figure 7.

5.4. Step 4: Product Modularization Using Multioptimization Model. The RMI, EODI, and CPI matrices are generated 


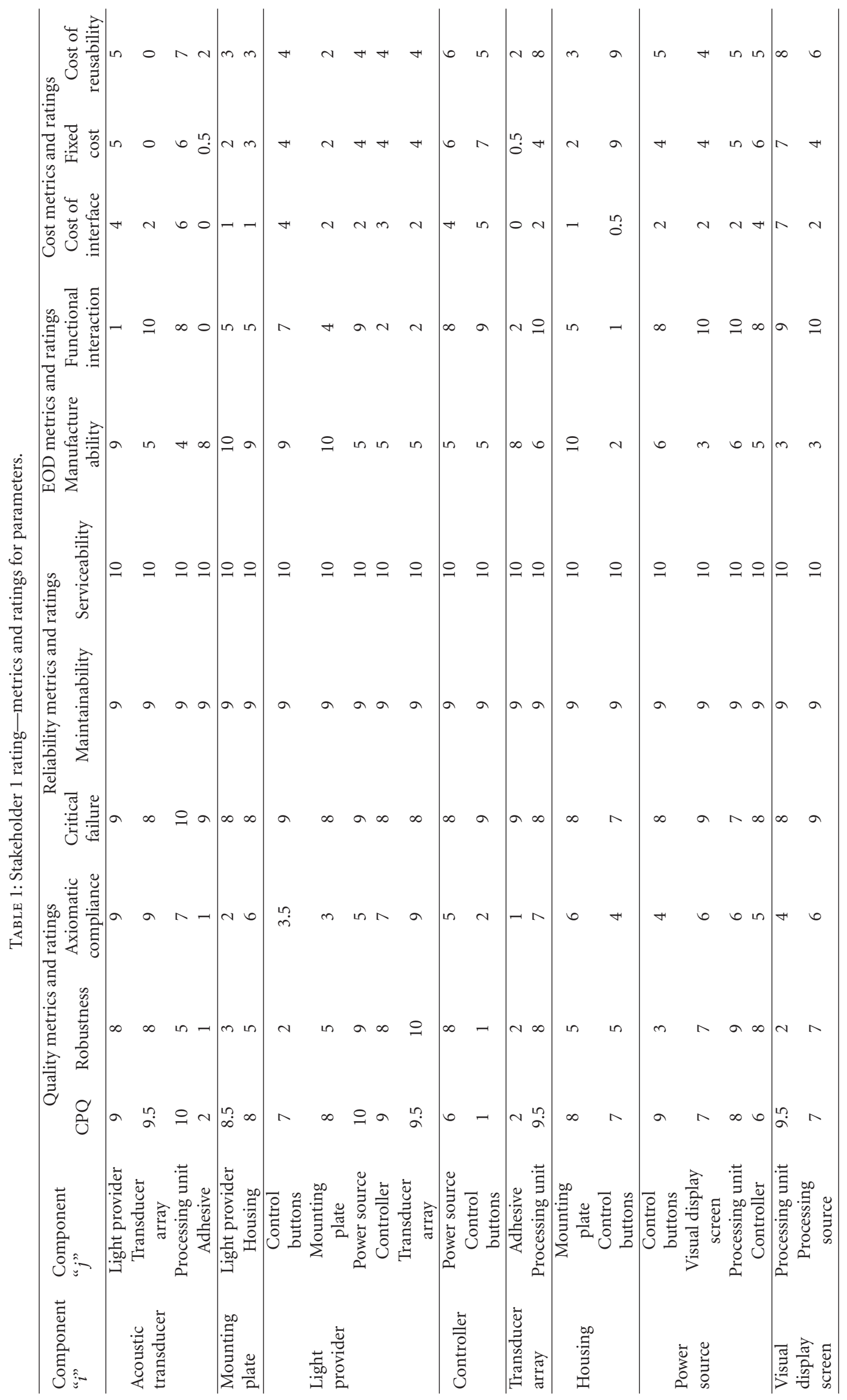




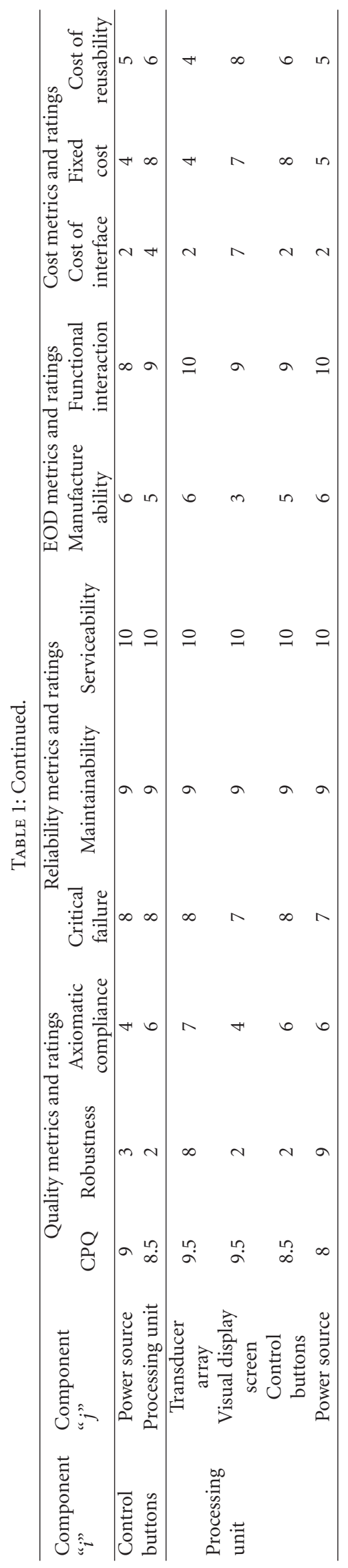




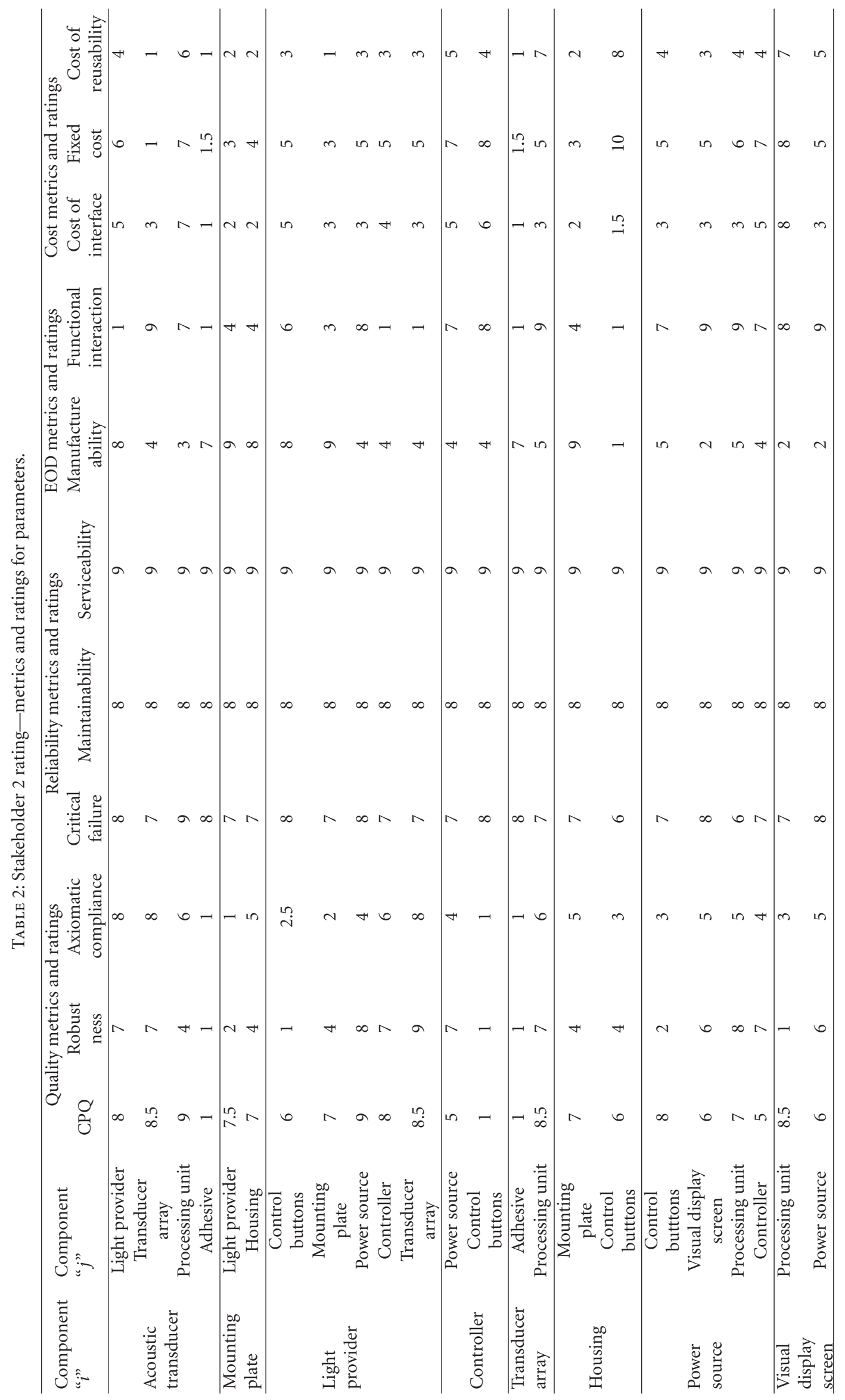




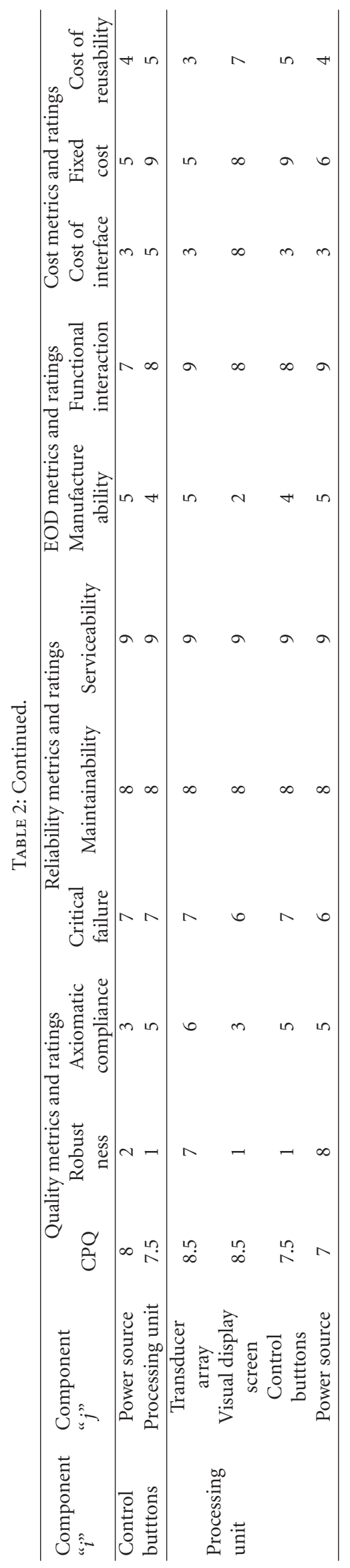


TABLE 3: Measurement parameters.

\begin{tabular}{|c|c|c|c|c|}
\hline \multirow{2}{*}{$\begin{array}{l}\text { Performance metric } \\
\text { type }\end{array}$} & \multicolumn{2}{|c|}{ Metric indicators (factors) } & \multicolumn{2}{|c|}{ Fuzzy output } \\
\hline & $\begin{array}{l}\text { Linguistic Variables } \\
\text { (input) }\end{array}$ & $\begin{array}{c}\text { Levels of linguistic } \\
\text { variables }\end{array}$ & Performance index & $\begin{array}{c}\text { Levels or values of } \\
\text { output variables }\end{array}$ \\
\hline Quality & $\begin{array}{l}\text { Customer perceived } \\
\text { quality }(\mathrm{CPQ}), \\
\text { robustness and } \\
\text { axiomatic compliance }\end{array}$ & $\begin{array}{l}\text { Very low, low, } \\
\text { moderate, high, very } \\
\text { high }\end{array}$ & $\begin{array}{l}\text { Quality robustness } \\
\text { index (QRI) }\end{array}$ & Crisp value $(1-10)$ \\
\hline Reliability & $\begin{array}{c}\text { Critical failure, } \\
\text { maintainability, and } \\
\text { serviceability }\end{array}$ & $\begin{array}{c}\text { Very low, low, } \\
\text { moderate, high, very } \\
\text { high }\end{array}$ & $\begin{array}{l}\text { Rmaintainability } \\
\text { index (RMI) }\end{array}$ & Crisp value $(1-10)$ \\
\hline $\begin{array}{l}\text { Ease of development } \\
\text { (EOD) }\end{array}$ & $\begin{array}{l}\text { Manufacturability of } \\
\text { the module and } \\
\text { functional interaction } \\
\text { between the } \\
\text { components }\end{array}$ & $\begin{array}{l}\text { Very low, low, } \\
\text { moderate, high, very } \\
\text { high }\end{array}$ & EOD index (EDI) & Crisp value (1-10) \\
\hline Cost & $\begin{array}{l}\text { Assembly cost, fixed } \\
\text { cost, and } \\
\text { standardizing cost }\end{array}$ & $\begin{array}{c}\text { Very low, low, } \\
\text { moderate, high, very } \\
\text { high }\end{array}$ & $\begin{array}{l}\text { Cost performance } \\
\text { index }(\mathrm{CPI})\end{array}$ & Crisp value $(1-10)$ \\
\hline
\end{tabular}

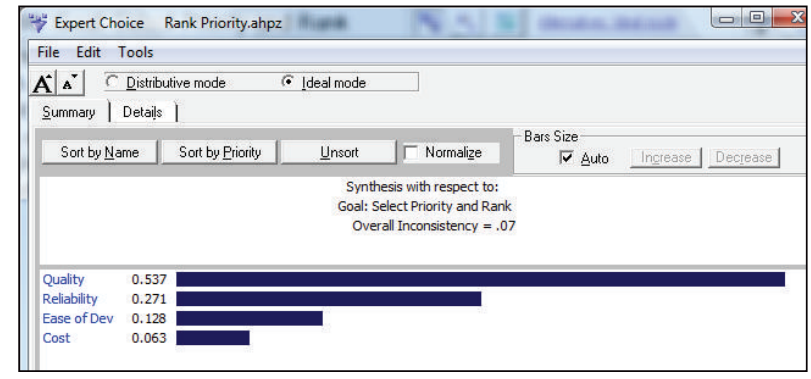

FIgURE 4: Expert choice output.

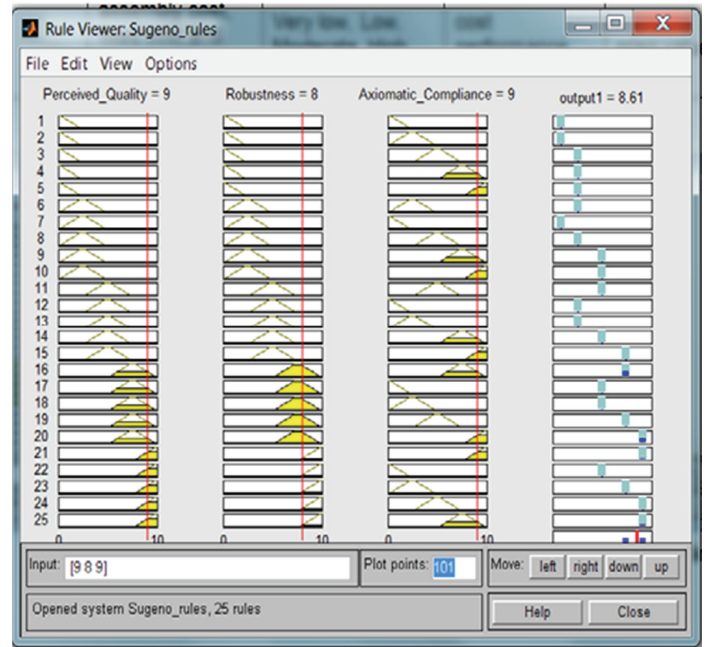

(a) Stakeholder 1 Rating

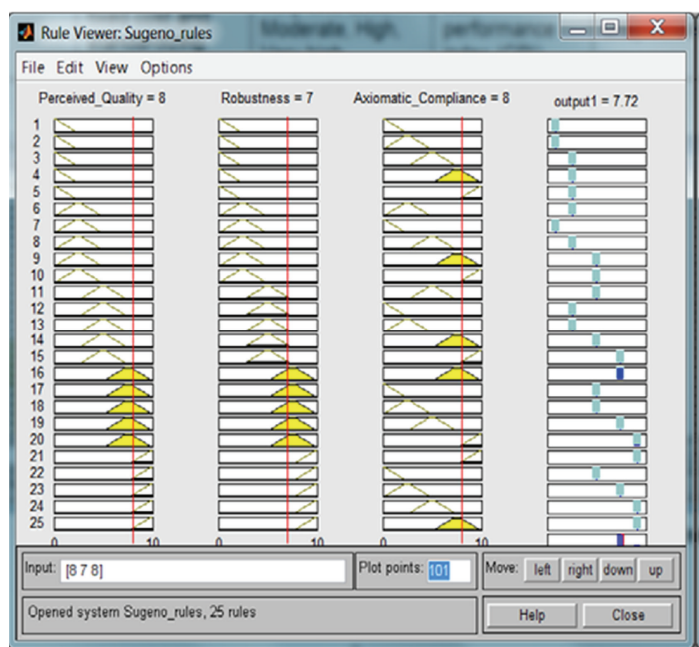

(b) Stakeholder 2 Rating

FIgURE 5: Rule viewer of Sugeno.

in a fashion similar to the QRI matrix. They are decision structure matrices (DSM), drawn to capture the fuzzy output values for each of the parameters based on the metrics defined under them. The crisp performance indices obtained from the fuzzy logic model are fed into individual optimization programs to compute a goal function for each of the performance metrics. Four individual optimization models are run for each of the parameters: quality, reliability, EOD, and cost. The details of the mathematical model are discussed in Section 4.2. 


\begin{tabular}{|c|c|c|c|c|c|c|c|c|c|c|c|c|}
\hline trix & & & & & & & & & & & & \\
\hline $\begin{array}{l}\text { Columns “j” } \\
\text { Rows “i” }\end{array}$ & \begin{tabular}{|l|} 
Accoustic \\
transducer
\end{tabular} & $\begin{array}{l}\text { Mounting } \\
\text { plate }\end{array}$ & $\begin{array}{c}\text { Light } \\
\text { provider }\end{array}$ & Controller & $\mid \begin{array}{c}\text { Transducer } \\
\text { array }\end{array}$ & Housing & $\begin{array}{l}\text { Power } \\
\text { source }\end{array}$ & \begin{tabular}{|l|} 
Visual \\
display \\
screen
\end{tabular} & $\begin{array}{l}\text { Control } \\
\text { buttons }\end{array}$ & Adhesive & $\begin{array}{c}\text { Prosessing } \\
\text { unit }\end{array}$ & \\
\hline Acoustic transducer & & 1 & 8.61 & 1 & 8.83 & 1 & 1 & 1 & 1 & 1.39 & 5 & \\
\hline Mounting plate & 1 & & 5 & 1 & 1 & 5 & 1 & 1 & 1 & 1 & 1 & \\
\hline Light provider & 8.61 & 5 & & 8.09 & 9.27 & 1 & 9.27 & 1 & 5 & 1 & 1 & \\
\hline Controller & 1 & 1 & 8.09 & & 1 & 1 & 7.5 & 1 & 1.26 & 1 & 1 & \\
\hline Transducer array & 8.83 & 1 & 9.27 & 1 & & 1 & 1 & 1 & 1 & 1.26 & 8.39 & \\
\hline Housing & 1 & 5 & 1 & 1 & 1 & & 1 & 1 & 3.75 & 1 & 1 & \\
\hline Power source & 1 & 1 & 9.27 & 7.5 & 1 & 1 & & 7 & 5 & 1 & 7.94 & \\
\hline Visual display screen & 1 & 1 & 1 & 1 & 1 & 1 & 7 & & 1 & 1 & 5 & \\
\hline Control buttons & 1 & 1 & 5 & 1.26 & 1 & 3.75 & 5 & 1 & & 1 & 5 & \\
\hline Adhesive & 1.39 & 1 & 1 & 1 & 1.26 & 1 & 1 & 1 & 1 & & 1 & \\
\hline Processing unit & 5 & 1 & 1 & 1 & 8.39 & 1 & 7.94 & 5 & 5 & 1 & & \\
\hline Decision variables $X_{i j}$ & & & & & & & & & & & & \\
\hline $\begin{array}{l}\text { Columns “ } j \text { ” } \\
\text { Rows “ } i \text { ” } \\
\end{array}$ & $\begin{array}{l}\text { Accoustic } \\
\text { transducer }\end{array}$ & $\begin{array}{l}\text { Mounting } \\
\text { plate }\end{array}$ & $\begin{array}{c}\text { Light } \\
\text { provider }\end{array}$ & Controller & $\begin{array}{c}\text { Transducer } \\
\text { array }\end{array}$ & Housing & $\begin{array}{l}\text { Power } \\
\text { source }\end{array}$ & \begin{tabular}{|c|} 
Visual \\
display \\
screen
\end{tabular} & \begin{tabular}{|l|} 
Control \\
buttons
\end{tabular} & Adhesive & $\begin{array}{c}\text { Processing } \\
\text { unit }\end{array}$ & \begin{tabular}{|c} 
Constraints \\
Sum of \\
$X_{11}, X_{12}$, \\
$X_{13}$
\end{tabular} \\
\hline Acoustic transducer & 0 & 0 & 0 & 0 & 1 & 0 & 0 & 0 & 0 & 0 & 0 & 1 \\
\hline Mounting plate & 0 & 1 & 0 & 0 & 0 & 0 & 0 & 0 & 0 & 0 & 0 & 1 \\
\hline Light provider & 0 & 0 & 0 & 0 & 0 & 0 & 1 & 0 & 0 & 0 & 0 & 1 \\
\hline Controller & 0 & 0 & 0 & 0 & 0 & 0 & 1 & 0 & 0 & 0 & 0 & 1 \\
\hline Transducer array & 0 & 0 & 0 & 0 & 1 & 0 & 0 & 0 & 0 & 0 & 0 & 1 \\
\hline Housing & 0 & 1 & 0 & 0 & 0 & 0 & 0 & 0 & 0 & 0 & 0 & 1 \\
\hline Power source & 0 & 0 & 0 & 0 & 0 & 0 & 1 & 0 & 0 & 0 & 0 & 1 \\
\hline Visual display screen & 0 & 0 & 0 & 0 & 0 & 0 & 0 & 0 & 0 & 0 & 0 & 1 \\
\hline Control buttons & 0 & 0 & 0 & 0 & 0 & 0 & 0 & 0 & 1 & 0 & 0 & 1 \\
\hline Adhesive & 0 & 0 & 0 & 0 & 0 & 0 & 0 & 0 & 0 & 1 & 0 & 1 \\
\hline Processing unit & 0 & 0 & 0 & 0 & 1 & 0 & 0 & 0 & 0 & 0 & 0 & 1 \\
\hline $\begin{array}{l}\text { Enter subjective } \\
\text { decision, } N\end{array}$ & 5 & & & & & & & & & & & \\
\hline $\begin{array}{l}\text { Quality goal function, } \\
Z_{q}\end{array}$ & 45.99 & & & & & & & & & & & \\
\hline
\end{tabular}

FIgURE 6: Quality goal function—stakeholder 1 ratings.

The Quality Goal Function $Z_{q}$ for stakeholder 1 rating is shown computed in Figure 6 and for stakeholder 2 rating in Figure 7. Similarly, reliability goal function $Z_{r}$, EOD goal function $Z_{e}$ and cost goal function $Z_{c}$ are calculated. $Z_{q}$, $Z_{r}, Z_{e}$, and $Z_{e}$ represent the aspiration levels for the goal programming model.

After determining the goal levels for each of the performance metrics, the final goal programming (GP) model is run to identify the optimal modules. The GP model is to be solved using the Excel-based Solver package from Frontline Systems. The final GP model with the optimal number of modules calculated for stakeholder 1 rating is shown in Figure 8 and for stakeholder 2 rating in Figure 9. In the final GP model, the decision variables are binary, that is, 0 or 1 .

The binary decision variables along the diagonal and the non diagonal binary variables each have different meanings [1]. Figure 8 shows the final GP module and the grouping of components. The optimal number of modules, $N^{*}$ is 2 . Module 1 consists of mounting plate, light provider, housing, power source, control buttons, and adhesive. Module 2 comprises acoustic transducer, controller, transducer array, visual display screen, and processing unit.

\section{Evaluation}

The goal program generates an optimal number of modules. The optimum solution can be affected by various parameters and metrics used in the study. These parameters, including stakeholder inputs, fuzzy rules, and choice of linear program and solver precision, by themselves can affect the optimal solution. The effect of changing the stakeholder inputs on the optimal number of modules and min deviation, $d$, is studied and presented for stakeholder 1 rating in Table 4 and stakeholder 2 rating in Table 5.

One of the critical parameters in the linear program is the initial module selection, $N$, which is a subjective decision of the OEM designer. We completed an analysis by varying $N$ in order to study the optimal number of modules, $N^{*}$. Tables 4 and 5 show that the goal programming model is sensitive to the subjective decision of the OEM designer. In Table 4, the optimal modules change for predefined modules $1,6,7,10$, and 11; the modules remain constant for predefined modules $2,3,4,5,8$, and 9. In Table 5, the optimal modules change for predefined modules $7,9,10$, and 11 and remain constant for all other values of $N$. 


\begin{tabular}{|c|c|c|c|c|c|c|c|c|c|c|c|c|}
\hline QPI matrix & & & & & & & & & & & & \\
\hline $\begin{array}{l}\text { Columns “ j” } \\
\text { Rows “i” }\end{array}$ & \begin{tabular}{|l|} 
Acoustic \\
transducer
\end{tabular} & $\begin{array}{l}\text { Mounting } \\
\text { plate }\end{array}$ & $\begin{array}{c}\text { Light } \\
\text { provider }\end{array}$ & Controller & $\begin{array}{c}\text { Transducer } \\
\text { array }\end{array}$ & Housing & $\begin{array}{l}\text { Power } \\
\text { source }\end{array}$ & \begin{tabular}{|l} 
Visual \\
display \\
screen
\end{tabular} & \begin{tabular}{|l|} 
Control \\
buttons
\end{tabular} & Adhesive & $\begin{array}{c}\text { Processing } \\
\text { unit }\end{array}$ & \\
\hline Accoustic transducer & & 1 & 7.98 & 1 & 8.33 & 1 & 1 & 1 & 1 & 0.933 & 5.48 & \\
\hline Mounting plate & 1 & & 1.26 & 1 & 1 & 2.75 & 1 & 1 & 1 & 1 & 1 & \\
\hline Light provider & 7.98 & 1.26 & & 7.17 & 8.48 & 1 & 5.69 & 1 & 1.11 & 1 & 1 & \\
\hline Controller & 1 & 1 & 7.17 & & 1 & 1 & 2.75 & 1 & 0.933 & 1 & 1 & \\
\hline Transducer array & 8.33 & 1 & 8.48 & 1 & & 1 & 1 & 1 & 1 & 0.933 & 6.96 & \\
\hline Housing & 1 & 2.75 & 1 & 1 & 1 & & 1 & 1 & 2.05 & 1 & 1 & \\
\hline Power source & 1 & 1 & 5.69 & 2.75 & 1 & 1 & & 4.46 & 2.73 & 1 & 7 & \\
\hline Visual display screen & 1 & 1 & 1 & 1 & 1 & 1 & 4.46 & & 1 & 1 & 2.29 & \\
\hline Control buttons & 1 & 1 & 1.11 & 0.933 & 1 & 2.05 & 2.73 & 1 & & 1 & 2.5 & \\
\hline Adhesive & 0.933 & 1 & 1 & 1 & 0.933 & 1 & 1 & 1 & 1 & & 1 & \\
\hline Processing unit & 5.48 & 1 & 1 & 1 & 6.96 & 1 & 7 & 2.29 & 2.5 & 1 & & \\
\hline Decision variables $X_{i j}$ & & & & & & & & & & & & \\
\hline $\begin{array}{l}\text { Columns “ } j \text { ” } \\
\text { Rows “ } i \text { " }\end{array}$ & \begin{tabular}{|l|} 
Acoustic \\
transducer
\end{tabular} & $\begin{array}{l}\text { Mounting } \\
\text { plate }\end{array}$ & $\begin{array}{c}\text { Light } \\
\text { provider }\end{array}$ & Controller & $\begin{array}{c}\text { Transducer } \\
\text { array }\end{array}$ & Housing & $\begin{array}{l}\text { Power } \\
\text { source }\end{array}$ & \begin{tabular}{|l} 
Visual \\
display \\
screen
\end{tabular} & $\begin{array}{l}\text { Control } \\
\text { buttons }\end{array}$ & Adhesive & $\begin{array}{c}\text { Processing } \\
\text { unit }\end{array}$ & $\begin{array}{c}\text { Sum of } \\
X_{11}, X_{12}, \\
X_{13}\end{array}$ \\
\hline Acoustic transducer & 0 & 0 & 1 & 0 & 0 & 0 & 0 & 0 & 0 & 0 & 0 & 1 \\
\hline Mounting plate & 0 & 1 & 0 & 0 & 0 & 0 & 0 & 0 & 0 & 0 & 0 & 1 \\
\hline Light provider & 0 & 0 & 1 & 0 & 0 & 0 & 0 & 0 & 0 & 0 & 0 & 1 \\
\hline Controller & 0 & 0 & 1 & 0 & 0 & 0 & 0 & 0 & 0 & 0 & 0 & 1 \\
\hline Transducer array & 0 & 0 & 1 & 0 & 0 & 0 & 0 & 0 & 0 & 0 & 0 & 1 \\
\hline Housing & 0 & 1 & 0 & 0 & 0 & 0 & 0 & 0 & 0 & 0 & 0 & 1 \\
\hline Power source & 0 & 0 & 0 & 0 & 0 & 0 & 1 & 0 & 0 & 0 & 0 & 1 \\
\hline Visual display screen & 0 & 0 & 0 & 0 & 0 & 0 & 1 & 0 & 0 & 0 & 0 & 1 \\
\hline Control buttons & 0 & 0 & 0 & 0 & 0 & 0 & 0 & 0 & 1 & 0 & 0 & 1 \\
\hline Adhesive & 0 & 0 & 0 & 0 & 0 & 0 & 0 & 0 & 0 & 1 & 0 & 1 \\
\hline Processing unit & 0 & 0 & 0 & 0 & 0 & 0 & 1 & 0 & 0 & 0 & 0 & 1 \\
\hline $\begin{array}{l}\text { Enter subjective } \\
\text { decision, } N\end{array}$ & 5 & & & & & & & & & & & \\
\hline $\begin{array}{l}\text { Quality goal function, } \\
\qquad Z_{q}\end{array}$ & 37.84 & & & & & & & & & & & \\
\hline
\end{tabular}

FIGURE 7: Quality goal function-stakeholder 2 ratings.

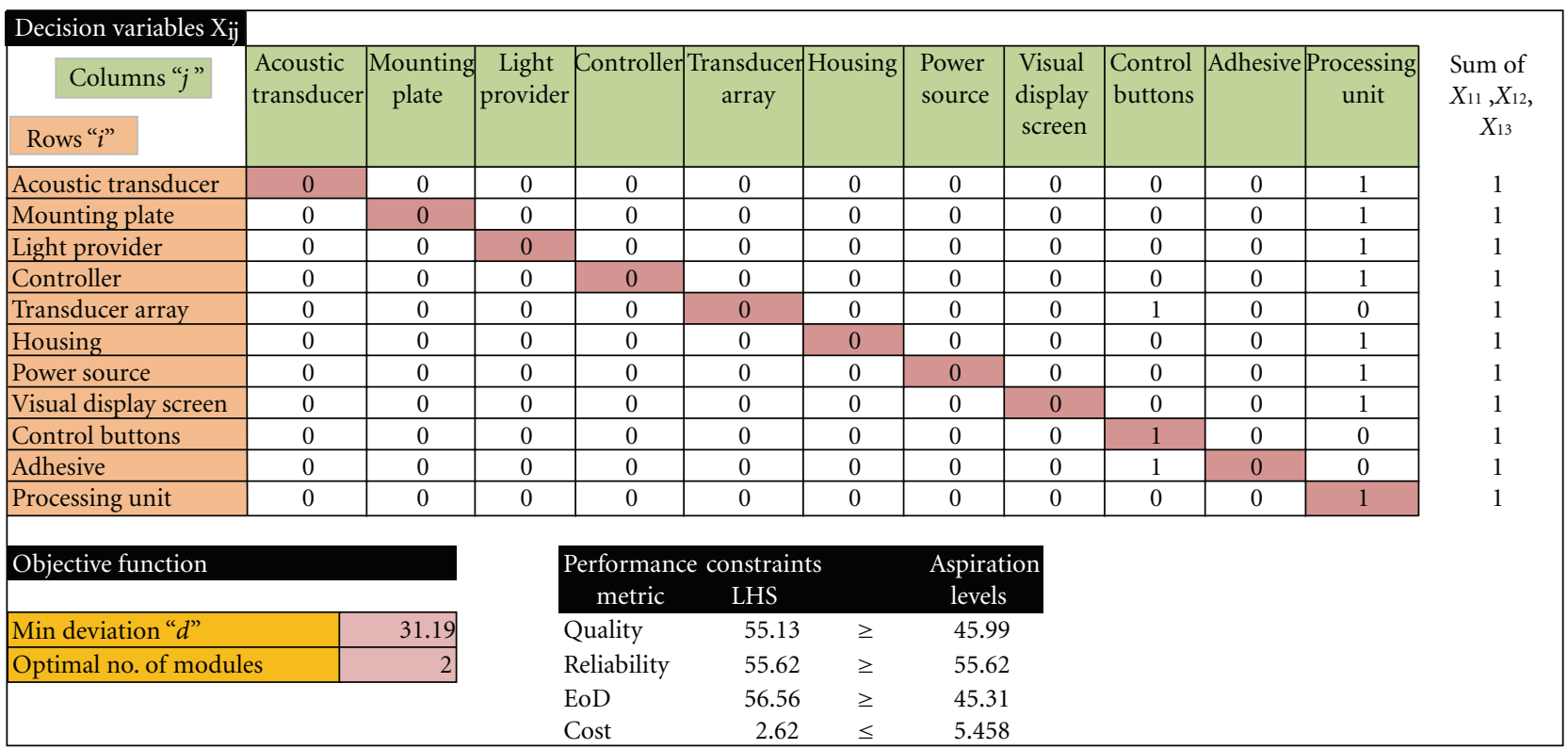

Figure 8: Final GP_optimal number of modules $N^{*}$ —stakeholder 1 rating. 


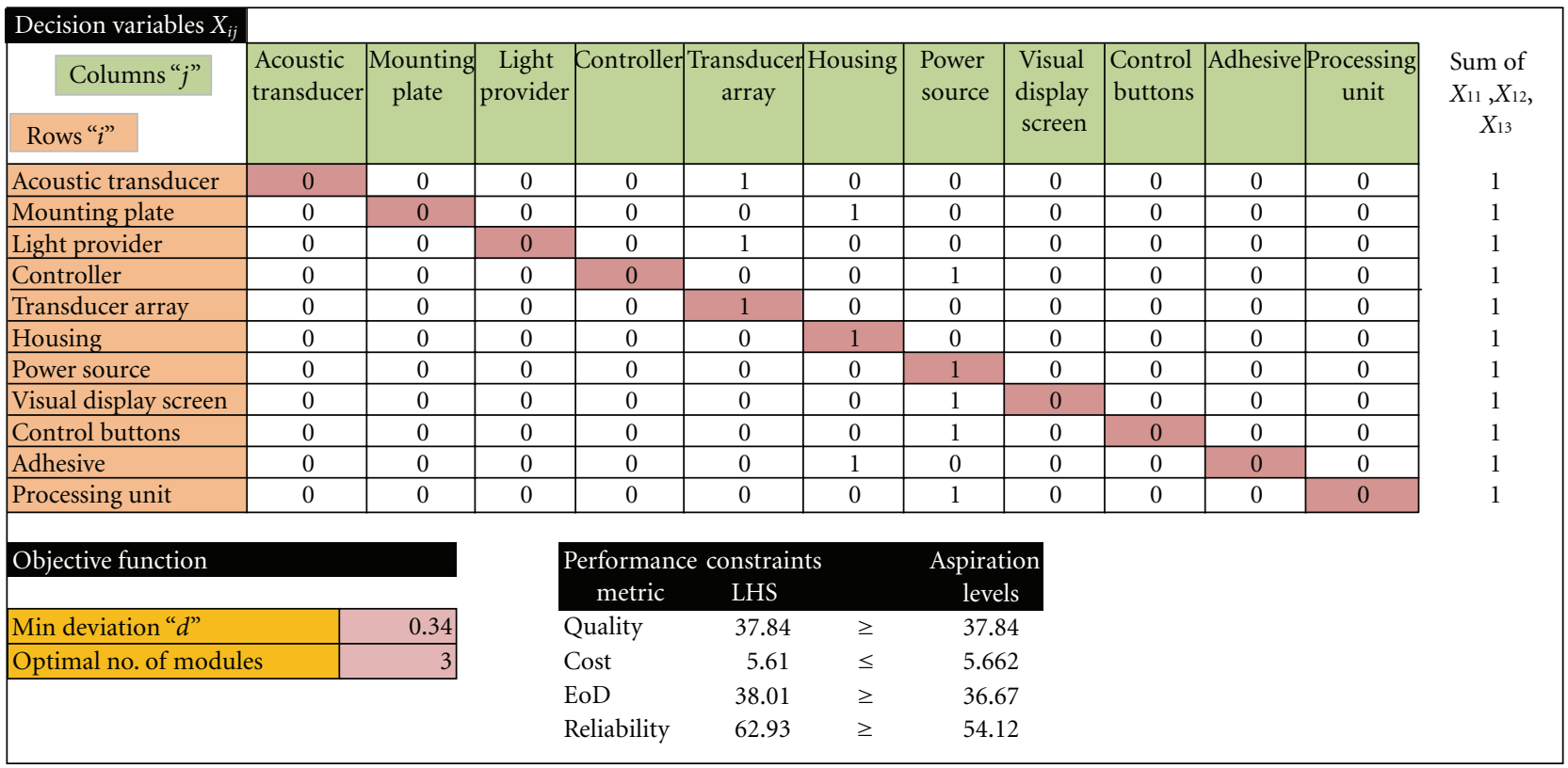

FIgURE 9: Final GP—optimal number of modules, $N^{*}$ —stakeholder 2 rating.

TABle 4: Effect of $N$ on optimal modules, $N^{*}$ and min deviation, $d$-stakeholder 1 rating.

\begin{tabular}{lcc}
\hline $\begin{array}{l}\text { Predefined no. of } \\
\text { modules, } N\end{array}$ & $\begin{array}{c}\text { Optimal modules, } \\
N^{*}\end{array}$ & Min deviation, $d$ \\
\hline 1 & 3 & 32.19 \\
2 & 2 & 38.46 \\
3 & 2 & 44.23 \\
4 & 2 & 36.46 \\
5 & 2 & 31.19 \\
6 & 5 & 26.35 \\
7 & 4 & 20.16 \\
8 & 2 & 14.81 \\
9 & 2 & 9.54 \\
10 & 6 & 4.27 \\
11 & 11 & $3.04 * 10^{-10}$ \\
\hline
\end{tabular}

TABle 5: Effect of $N$ on optimal modules, $N^{*}$ and min deviation, $d$-stakeholder 2 rating.

\begin{tabular}{lcc}
\hline $\begin{array}{l}\text { Predefined no. of } \\
\text { modules, } N\end{array}$ & $\begin{array}{c}\text { Optimal modules, } \\
N^{*}\end{array}$ & Min deviation, $d$ \\
\hline 1 & 3 & 0.007 \\
2 & 3 & 3.647 \\
3 & 3 & 4.137 \\
4 & 3 & 3.07 \\
5 & 3 & 0.34 \\
6 & 3 & 0.02 \\
7 & 4 & 0 \\
8 & 3 & 0 \\
9 & 4 & 0 \\
10 & 9 & 0 \\
11 & 10 & 0 \\
\hline
\end{tabular}

\section{Conclusion}

The goal of the objective function is to reduce minimum deviation. In Table 4 , the minimum " $d$ " value achieved is $3.04 \times 10^{-4}$. From Table 5, it can be seen that a zero minimum deviation is achieved when the predefined number of modules $(N)$ ranges from 7 to 11 . It can thus be inferred that stakeholder 2 rating is better than stakeholder 1 rating with respect to achieving minimum deviation and generating practical values of optimal modules $\left(N^{*}\right)$. This research will be extended to span minimally invasive and invasive medical devices such as artificial hearts.

\section{References}

[1] C. C. Aguwa, L. Monplaisir, P. A. Sylajakumari, and R. K. Muni, "Integrated fuzzy-based modular architecture for medical device design and development," Journal of Medical Devices, vol. 4, no. 3, Article ID 031007, 10 pages, 2010.

[2] C. Aguwa, L. Monplaisir, and A. S. Prasanth, "Rules modification on a fuzzy-based modular architecture for medical device design and development," IIE Transactions on Healthcare Systems Engineering, vol. 2, no. 1, pp. 50-61, 2012.

[3] G. Pahl and W. Beitz, Engineering Design: a Systematic Approach, Springer, London, UK, 2nd edition, 1984.

[4] B. Nepal, L. Monplaisir, and N. Singh, "Integrated fuzzy logic-based model for product modularization during concept development phase," International Journal of Production Economics, vol. 96, no. 2, pp. 157-174, 2005.

[5] C. Aguwa and L. Monplaisir, "Collaborative architecture framework for the design \& manufacturing of medical devices," in Proceedings of the Portland International Conference on Management of Engineering and Technology (PICMET '09), pp. 2246-2249, August 2009.

[6] C. C. Aguwa and L. Monplaisir, "Modular architecture for medical device design \& manufacturing," in Proceedings of the IIE Annual Conference, Miami, Fla, USA, 2009. 
[7] P. Dunne, "Design and manufacture of a multiple material sample for implantation testing of thermoplastic materials used in a medical device," Polymer Testing, vol. 24, no. 6, pp. 684-687, 2005.

[8] P. McAllister and J. Jeswiet, "Medical device regulation for manufacturers," Proceedings of the Institution of Mechanical Engineers, Part H: Journal of Engineering in Medicine, vol. 217, no. 6, pp. 459-467, 2003.

[9] S. Sanderson and M. Uzumeri, "Managing product families: the case of the Sony Walkman," Research Policy, vol. 24, no. 5, pp. 761-782, 1995.

[10] T. W. Simpson and B. S. D’Souza, "Assessing variable levels of platform commonality within a product family using a multiobjective genetic algorithm," Concurrent Engineering Research and Applications, vol. 12, no. 2, pp. 119-129, 2004.

[11] T. W. Simpson, J. R. Maier, and F. Mistree, "Product platform design: method and application," Research in Engineering Design, vol. 13, no. 1, pp. 2-22, 2001.

[12] Intertek, "The top 10 reasons medical devices fail-product certification testing the first time," 2008, http://www.interteketlsemko.com.

[13] Blachford, "Glucometer test kit, how products are made?" 2002, http://www.enotes.com/how-products-encyclopedia/ glucometer-test-kit.

[14] S. K. Das and J. B. Almonor, "A concurrent engineering approach for the development of medical devices," International Journal of Computer Integrated Manufacturing, vol. 13, no. 2, pp. 139-147, 2000.

[15] R. M. T. Lu and K. A. Mazouz, "A conceptual model of data warehousing for medical device manufacturers," in Proceedings of the 22nd Annual International Conference of the IEEE Engineering in Medicine and Biology Society, pp. 12791284, Chicago, Ill, USA, July 2000.

[16] R. C. Newton, O. T. Mytton, R. Aggarwal et al., "Making existing technology safer in healthcare," Quality \& Safety Healthcare, vol. 19, supplement 2, pp. 15-24, 2010.

[17] Q. H. Yang, G. N. Qi, Y. J. Lu, and X. J. Gu, "Applying mass customization to the production of industrial steam turbines," International Journal of Computer Integrated Manufacturing, vol. 20, no. 2-3, pp. 178-188, 2007.

[18] B. Nepal, L. Monplaisir, and N. Singh, "A methodology to optimize reliability and durability of product architecture through modularization," in Proceedings of the IIE Annual Conference and Exhibition, pp. 1257-1262, May 2004.

[19] T. Takagi and M. Sugeno, "Fuzzy identification of systems and its applications to modeling and control," IEEE Transactions on Systems, Man and Cybernetics, vol. 15, no. 1, pp. 116-132, 1985.

[20] B. Zhang, Y. Wu, J. Lu, and K. L. Du, "Evolutionary computation and its applications in neural and fuzzy systems," Applied Computational Intelligence and Soft Computing, vol. 2011, Article ID 938240, 20 pages, 2011.

[21] Y. Yi-Min, Y. Yan, and L. Li, "Adaptive backstepping fuzzy control based on type-2 fuzzy system," Journal of Applied Mathematics, vol. 2012, Article ID 658424, 27 pages, 2012.

[22] A. M. Subiyanto, "Hopfield neural network optimized fuzzy logic controller for maximum power point tracking in a photovoltaic system," International Journal of Photoenergy, vol. 2012, Article ID 798361, 13 pages, 2012.

[23] T. Zhao, G. Lu, Y. Hao, and Y. Li, "The hybrid adaptive control of T-S fuzzy system based on niche," Journal of Applied Mathematics, vol. 2012, Article ID 158720, 15 pages, 2012.

[24] F. Villecco and A. Pellegrino, "Design optimization of a natural gas substation with intensification of the energy cycle,"
Mathematical Problems in Engineering, vol. 2010, Article ID 294102, 10 pages, 2010.

[25] H. S. Sii, T. Ruxton, and J. Wang, "A fuzzy-logic-based approach to qualitative safety modelling for marine systems," Reliability Engineering and System Safety, vol. 73, no. 1, pp. 1934, 2001.

[26] Y. T. Tsai and K. S. Wang, "Development of modularbased design in considering technology complexity," European Journal of Operational Research, vol. 119, no. 3, pp. 692-703, 1999.

[27] O. P. Yadav, N. Singh, R. B. Chinnam, and P. S. Goel, "A fuzzy logic based approach to reliability improvement estimation during product development," Reliability Engineering and System Safety, vol. 80, no. 1, pp. 63-74, 2003.

[28] C. Temponi, J. Yen, and W. A. Tiao, "House of quality: a fuzzy logic-based requirements analysis," European Journal of Operational Research, vol. 117, no. 2, pp. 340-354, 1999.

[29] T. A. Saaty, Theory and Applications of the Analytical Network Process: Decision Making With Benefits, Opportunities, Cost and Risks, Pittsburgh-RWS Publications, 2005.

[30] A. A. Yassine, "An introduction to modeling and analyzing complex product development processes using the design structure matrix (DSM) method," Quaderni Di Management, no. 9, 2004.

[31] S. M. Salhieh and A. K. Kamrani, "Macro level product development using design for modularity," Robotics and ComputerIntegrated Manufacturing, vol. 15, no. 4, pp. 319-329, 1999.

[32] B. Pesach, "Wearable glucometer," Patent EP 1711101, (European Application Register), 2006.

[33] N. P. Suh, "Designing-in of quality through axiomatic design," IEEE Transactions on Reliability, vol. 44, no. 2, pp. 256-264, 1995.

[34] T. C. Kuo, S. H. Huang, and H. C. Zhang, "Design for manufacture and design for ' $\mathrm{X}$ ': concepts, applications, and perspectives," Computers and Industrial Engineering, vol. 41, no. 3, pp. 241-260, 2001. 

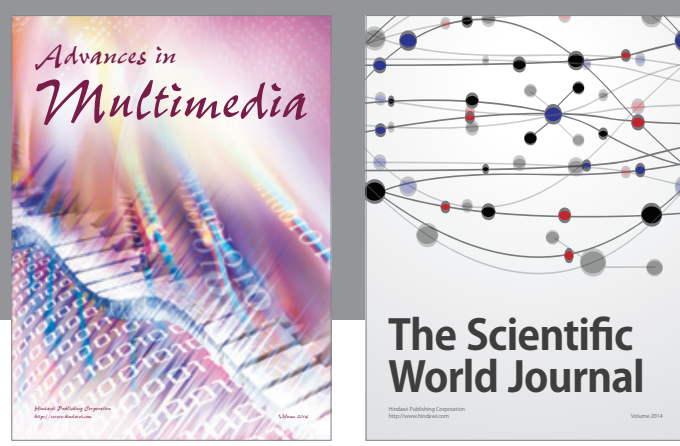

The Scientific World Journal
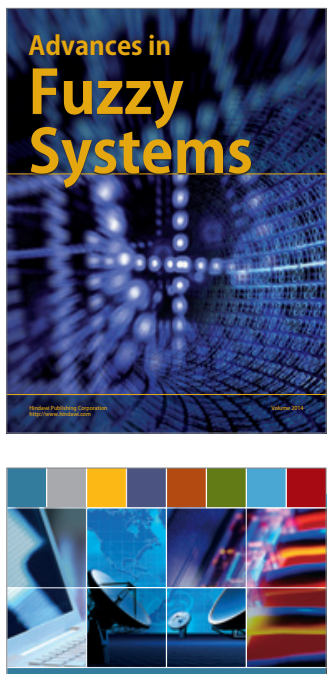

Computer Networks and Communications
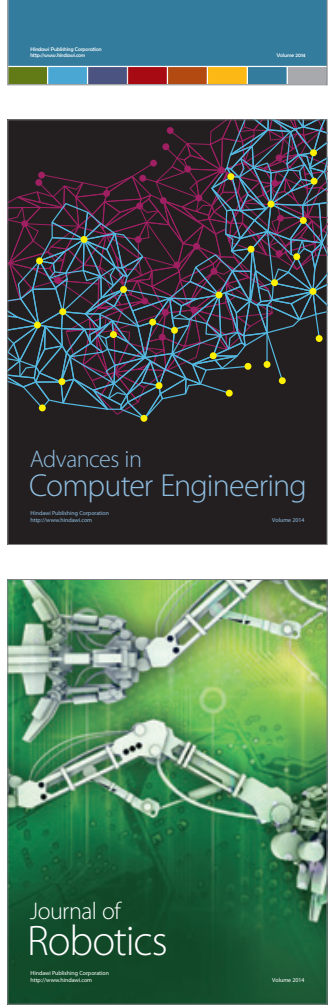
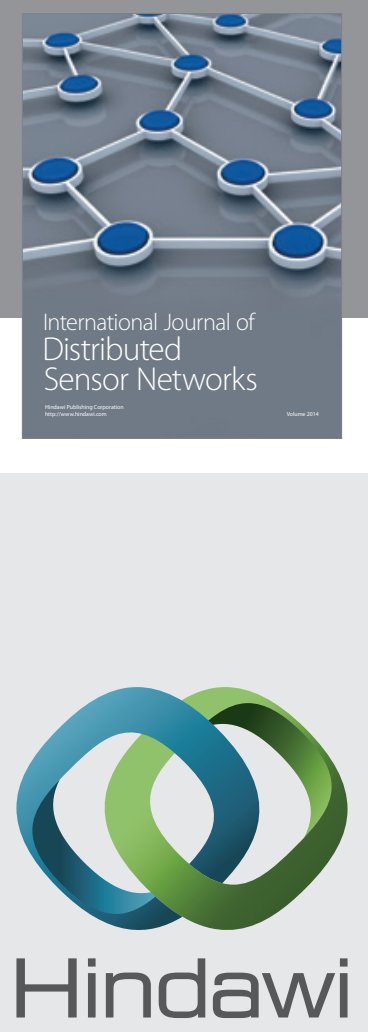

Submit your manuscripts at

http://www.hindawi.com
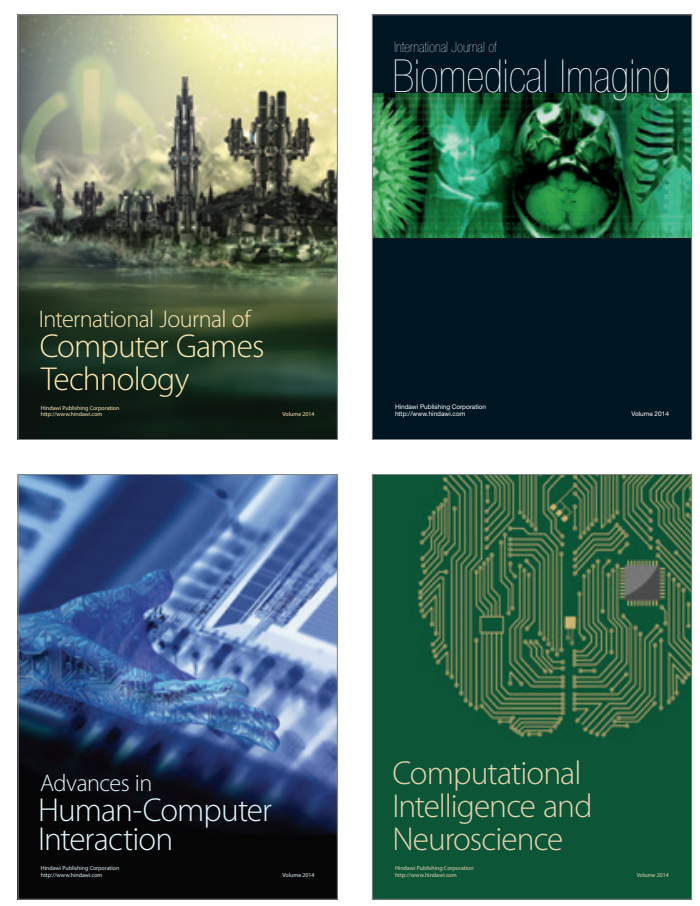
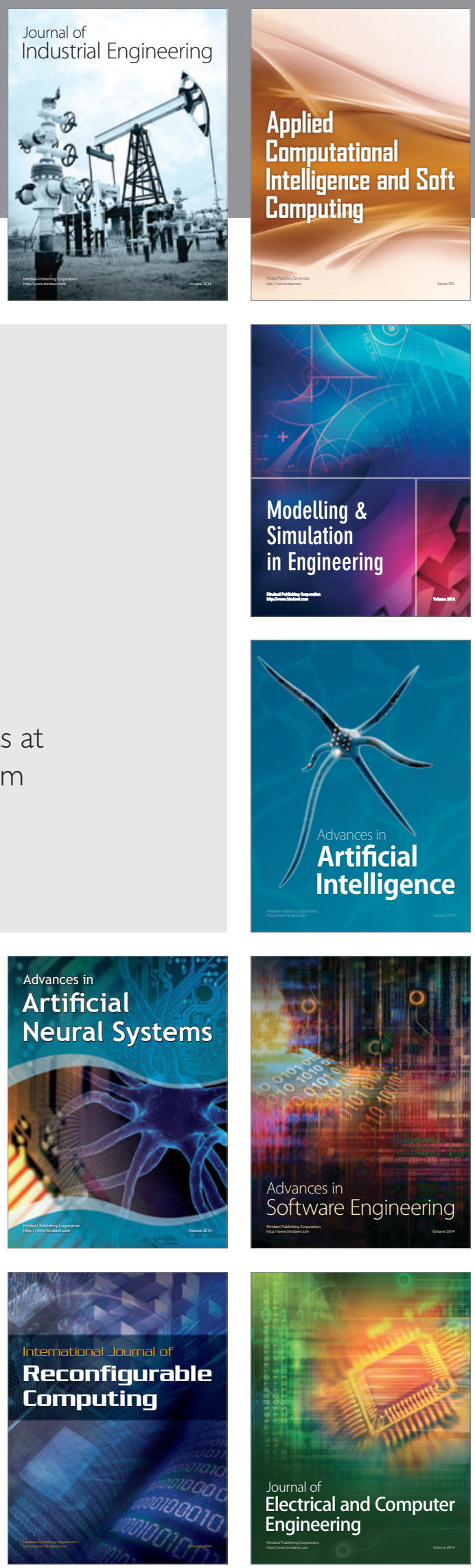